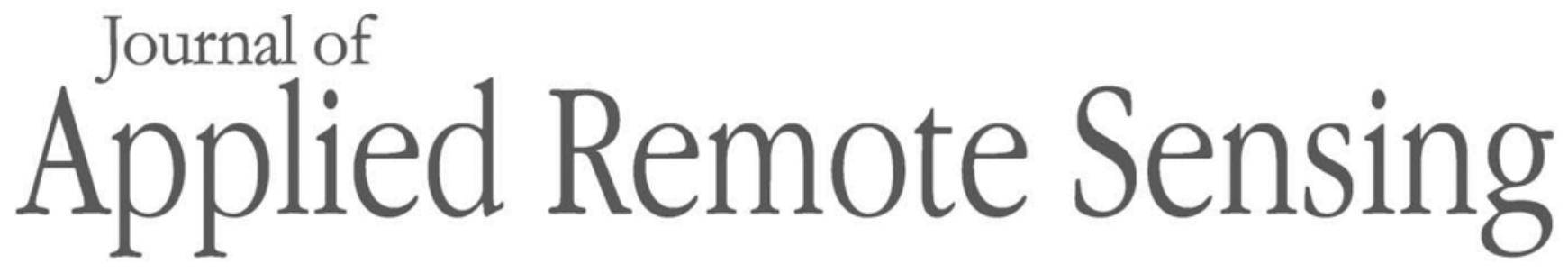

RemoteSensing.SPIEDigitalLibrary.org

\title{
Airborne lidar detection of an underwater thermal vent
}

Michael R. Roddewig

James H. Churnside

Joseph A. Shaw 


\title{
Airborne lidar detection of an underwater thermal vent
}

\author{
Michael R. Roddewig, ${ }^{a}$ James H. Churnside, ${ }^{\mathrm{b}}$ and Joseph A. Shaw ${ }^{\mathrm{a}}$ 网 \\ ${ }^{a}$ Montana State University, Electrical and Computer Engineering Department, \\ Bozeman, Montana, United States \\ ${ }^{b}$ National Oceanic and Atmospheric Administration, Earth Systems Research Laboratory, \\ Boulder, Colorado, United States
}

\begin{abstract}
We report the lidar detection of an underwater feature that appears to be a thermal vent in Yellowstone Lake, Yellowstone National Park, USA, with the Montana State University Fish Lidar. The location of the detected vent was $30 \mathrm{~m}$ from the closest vent identified in a United States Geological Survey of Yellowstone Lake in 2008. A second possible vent is also presented, and the appearance of both vents in the lidar data is compared to descriptions of underwater thermal vents in Yellowstone Lake from the geological literature. (c) 2017 Society of PhotoOptical Instrumentation Engineers (SPIE) [DOI: 10.1117/11.JRS.111.036014]
\end{abstract}

Keywords: airborne lidar; underwater thermal vents; remote sensing; Yellowstone National Park.

Paper 170383 received May 4, 2017; accepted for publication Jul. 28, 2017; published online Aug. 23, 2017.

\section{Introduction}

Yellowstone National Park, Wyoming, USA, is famous for its numerous geysers, hot springs, and other thermal features. While these features have been known of and studied since the 1800s, the existence of thermal activity in Yellowstone Lake itself was not realized until the 1980s. Several studies of these underwater thermal features have been undertaken since then, utilizing scuba divers, remotely operated vehicles (ROVs), and high-resolution echo sounder. HQ $^{\text {G }}$ Figure 1 is an example photograph of one of these vents, captured from an ROV.

Remsen et al. ${ }^{\mathbb{a}}$ and Morgan et al. ${ }^{\mathbb{9}}$ both report that many underwater vents emit bubbles of steam and $\mathrm{CO}_{2}$ gas. Often these vents exist in domal structures where the sediments have been forced upward by the gas or created by sediments entrained in the gas bubbles. These domes may rise to several meters in height. ${ }^{\mathrm{B}}$ The heated water and various chemicals emitted by these vents have a significant influence on the geochemical composition of Yellowstone Lake and its flora and fauna.

The underwater vents are often surrounded by diverse communities of bacteria, plants, and animals that would not typically exist in a cold, oligotrophic lake. West Thumb Geyser Basin was dubbed "Cutthroat Jacuzzi" because of the cutthroat trout that school to feed on the numerous zooplankton that live around it. ${ }^{\mathbb{T}}$

While underwater vents in Yellowstone have been detected and surveyed through direct observation (by scuba divers and ROVs) ${ }^{\text {国 }}$ and echo sounder, to the authors' knowledge the detection of thermal vents by lidar has not been previously reported.

\section{Lidar Detection of an Underwater Thermal Vent}

On September 28, 2016, we undertook a flight of Yellowstone Lake using the Montana State University (MSU) Fish Lidar. The details of this lidar have been previously reported in Ref. 9, and we will only briefly summarize its design here. The MSU Fish Lidar is a 532-nm,

*Address all correspondence to: Joseph A. Shaw, E-mail: Osephishaw@montanąedu

$1931-3195 / 2017 / \$ 25.00$ (C) 2017 SPIE 




Fig. 1 A hydrothermal vent in Yellowstone Lake viewed by the ROV "Yogi" in 2016. Photograph courtesy Global Foundation for Ocean Exploration, used with permission.

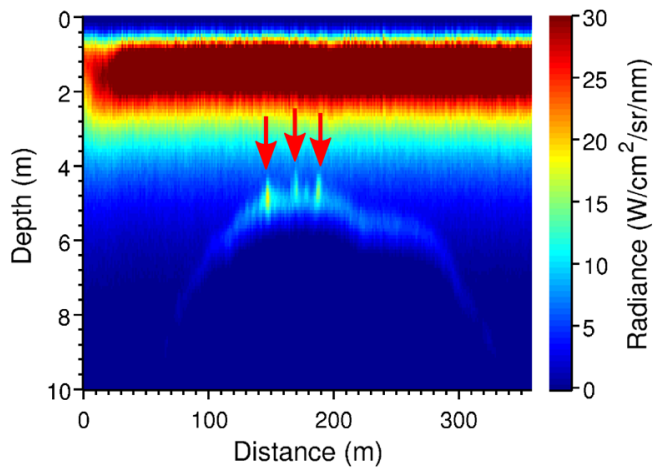

(a)



(b)



(c)

Fig. 2 Lidar image from the (a) copolarized channel, (b) cross-polarized channel, and (c) depolarization image of a suspected underwater thermal vent, which appears to be three vents in close proximity, in Yellowstone Lake at the West Thumb Geyser Basin. Red arrows indicate the location of the three suspected underwater thermal vents in the co- and cross-polarized image. To better display the suspected vent the scale was chosen such that the upper $\approx 2 \mathrm{~m}$ of water in the copolarized image is clipped. The bottom appears several meters thick in the image due to the temporal spread of the laser pulse. The location of the actual bottom is indicated by an arrow in the depolarization image, which is clipped at 1 . The cross-polarized bottom appears thicker due to increased temporal stretching caused by multiple scattering. The second "white layer" in the depolarization image is actually background light, as the laser pulse has completely decayed by this point. We postulate that this vent is active, given the bright returns from the vent holes which may be caused by entrained sediments or bubbles, 1 and the presence of the subsurface plume, which is possibly plankton. 
direct-detection, pulsed lidar, that is capable of measuring both co- and cross-polarized backscatter signals. The spot diameter on the water surface is $5 \mathrm{~m}$, and the penetration depth is typically $12 \mathrm{~m}$. The primary purpose of this flight was to survey for invasive lake trout (these results are to be reported in an upcoming article), and portions of the flight were conducted in the West Thumb area, near the West Thumb Geyser Basin.

Figure 2 shows a lidar image and Fig. 3 shows a lidar profile of the suspected thermal vent, which appears to actually be three vents in close proximity at a depth of approximately $4 \mathrm{~m}$. The location was at $44.424745^{\circ} \mathrm{N}, 110.571984^{\circ} \mathrm{W}$, located within the $500-\mathrm{m}$ diameter hydrothermal

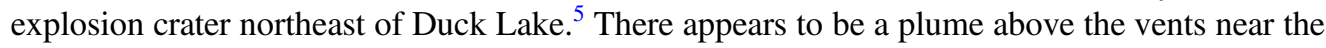
water surface. Each vent has a strong return associated with it, possibly caused by entrained sediments which are common in the vent water ${ }^{\square}$ The dome-shaped structure has been reported as a characteristic of some hydrothermal vents in Yellowstone Lake, as mentioned in Sec. Figure $\mathrm{Q}$ is a photograph taken from the plane of the area where the vent was identified. The reddish-brown slick appears to be the plume that was seen in the lidar data near the water surface.

We believe the plume near the water surface is most likely plankton. Hydrothermal vents in Yellowstone commonly release bubbles, $\mathbb{Q}$ but if these were present we would expect to see a stream from the location of the vent to the surface, $\square$ which we do not.

Figure 5 shows a map of thermal vents from a 2007 United States Geological Survey (USGS) study performed by Morgan et al ${ }^{\mathbb{1 0}}$ and the thermal vent discussed above. The nearest vent location from this study is only $30 \mathrm{~m}$ away, which is a very reasonable error given that the

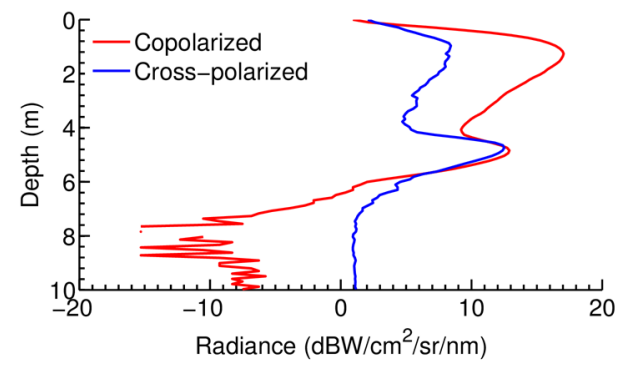

(a)

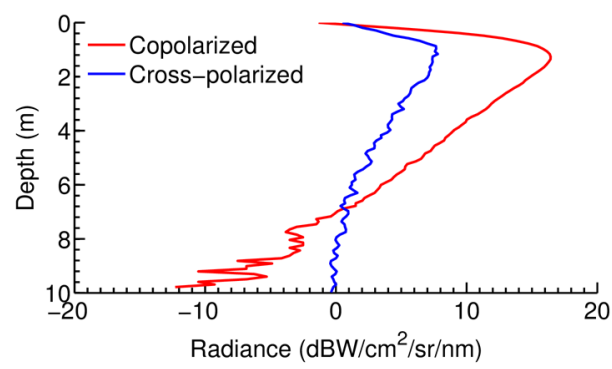

(b)

Fig. 3 Plot of the lidar signal from over the thermal vent shown in Fig. 2(a) and for comparison the lidar signal from clear water (b) in units of $\mathrm{dB}$ radiance. Each channel has been offset slightly due to the calibration sometimes reporting negative radiance at small values, which also manifests in the cross-polarized radiance being greater than the copolarized radiance at deeper depths.

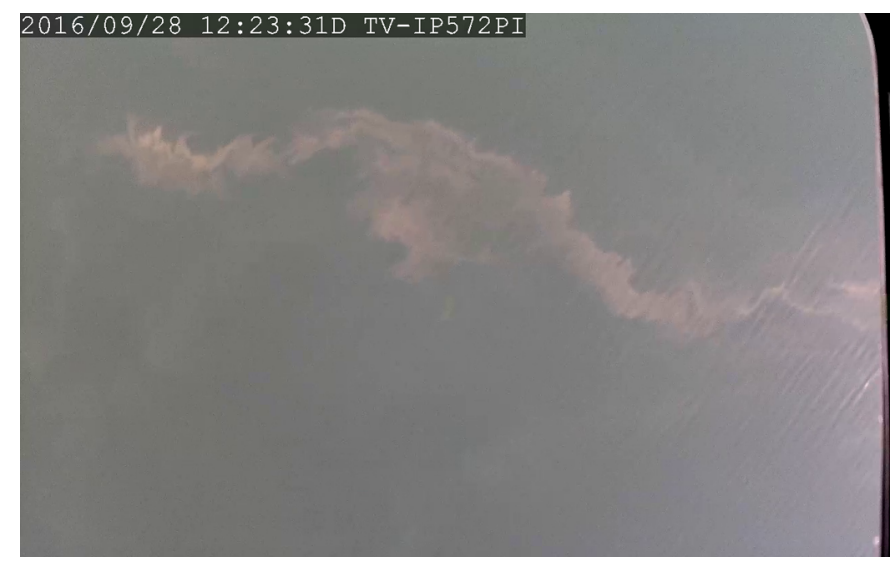

Fig. 4 A picture taken from the plane of the thermal vent identified in Fig. 目. The reddish-brown slick is presumably the same slick that was seen near the surface in the lidar data. 


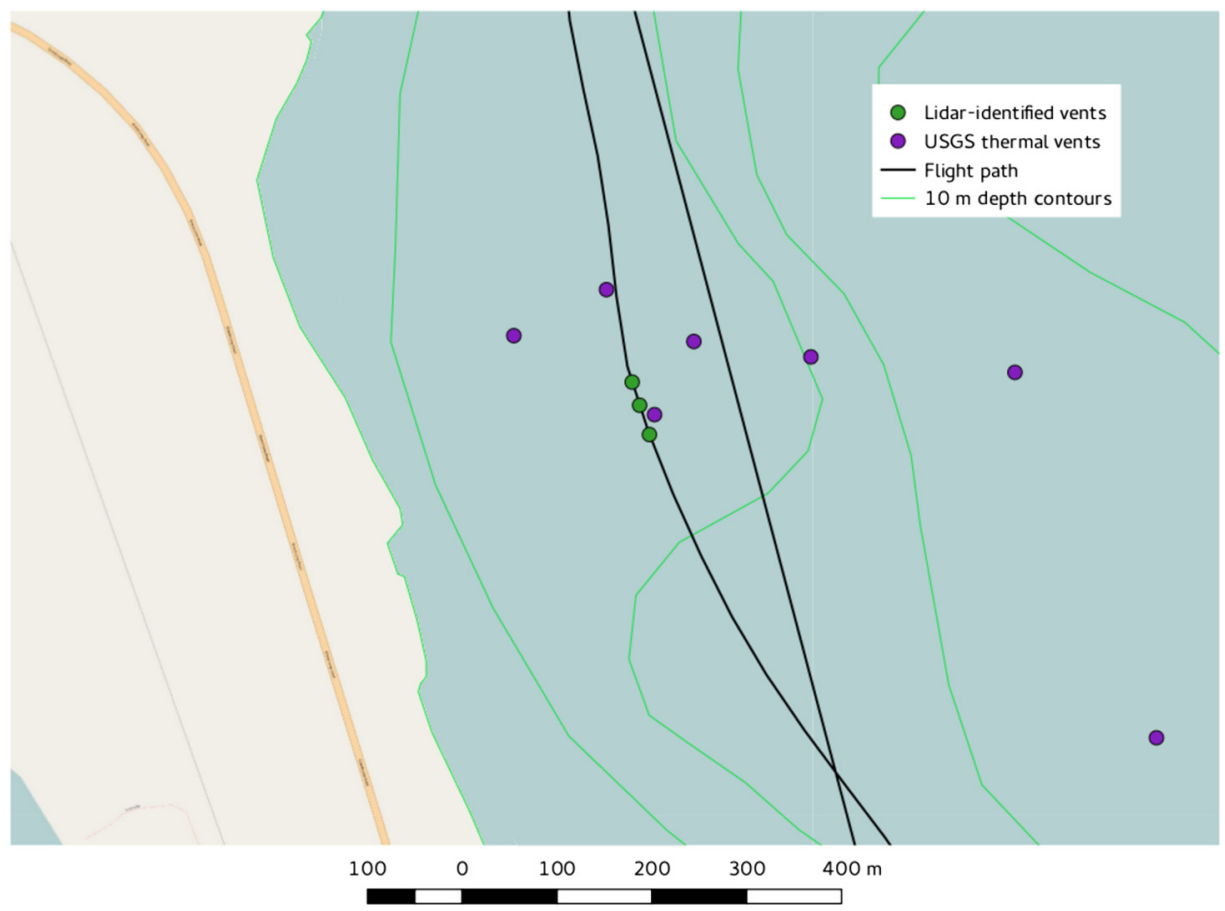

Fig. 5 A map showing USGS-identified thermal vents and the location of the vent shown in Fig. 8 The nearest USGS-identified thermal vent is $30 \mathrm{~m}$ away. Top of the maps point north. Thermal vent and bathymetry data from Ref. 8 . Base map data @ OpenStreetMap contributors.

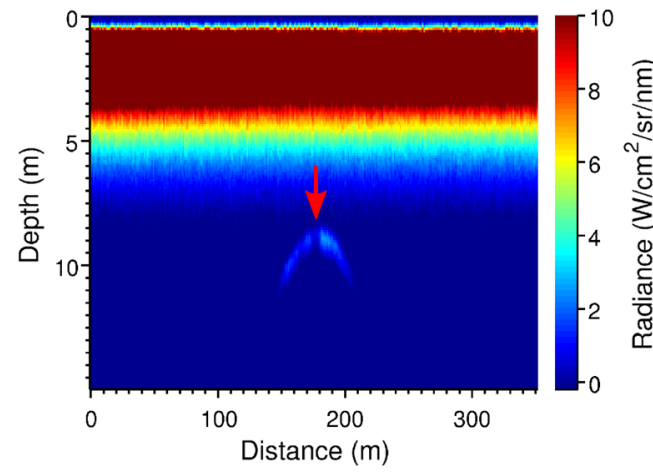

(a)

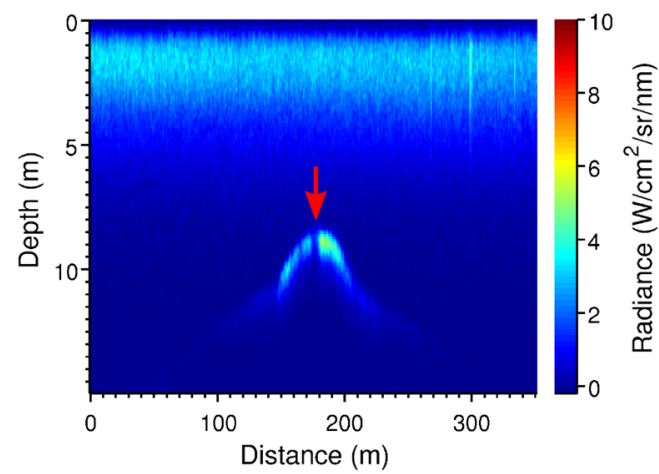

(b)

Fig. 6 Lidar image from the (a) copolarized channel and (b) cross-polarized channel of a second suspected underwater thermal vent in Yellowstone Lake at the West Thumb Geyser Basin, indicated by the red arrow. This vent is possibly inactive as there was no subsurface plume associated with it, and the vent hole return was dark.

tilt of the plane is not currently accounted for when computing the location of the lidar shots, and the global positioning system unit is often only accurate to $10 \mathrm{~m}$.

Figure 6 shows a lidar image of a second suspected thermal vent at a depth of approximately $8.5 \mathrm{~m}$, also in the West Thumb Geyser Basin. The location was at $44.468268^{\circ} \mathrm{N}, 110.546503^{\circ} \mathrm{W}$. The depolarization image was not included because the signal is completely depolarized beyond $7 \mathrm{~m}$. The photograph of the area captured from the plane was unremarkable, showing no evidence of a surface slick as with the previous vent. This vent shares the same domal structure as the previous vent. This vent is $67 \mathrm{~m}$ from the closest vent in the USGS data. Figures 7 and 8 show a map of the vent location in relation to the vents identified in the USGS study. 


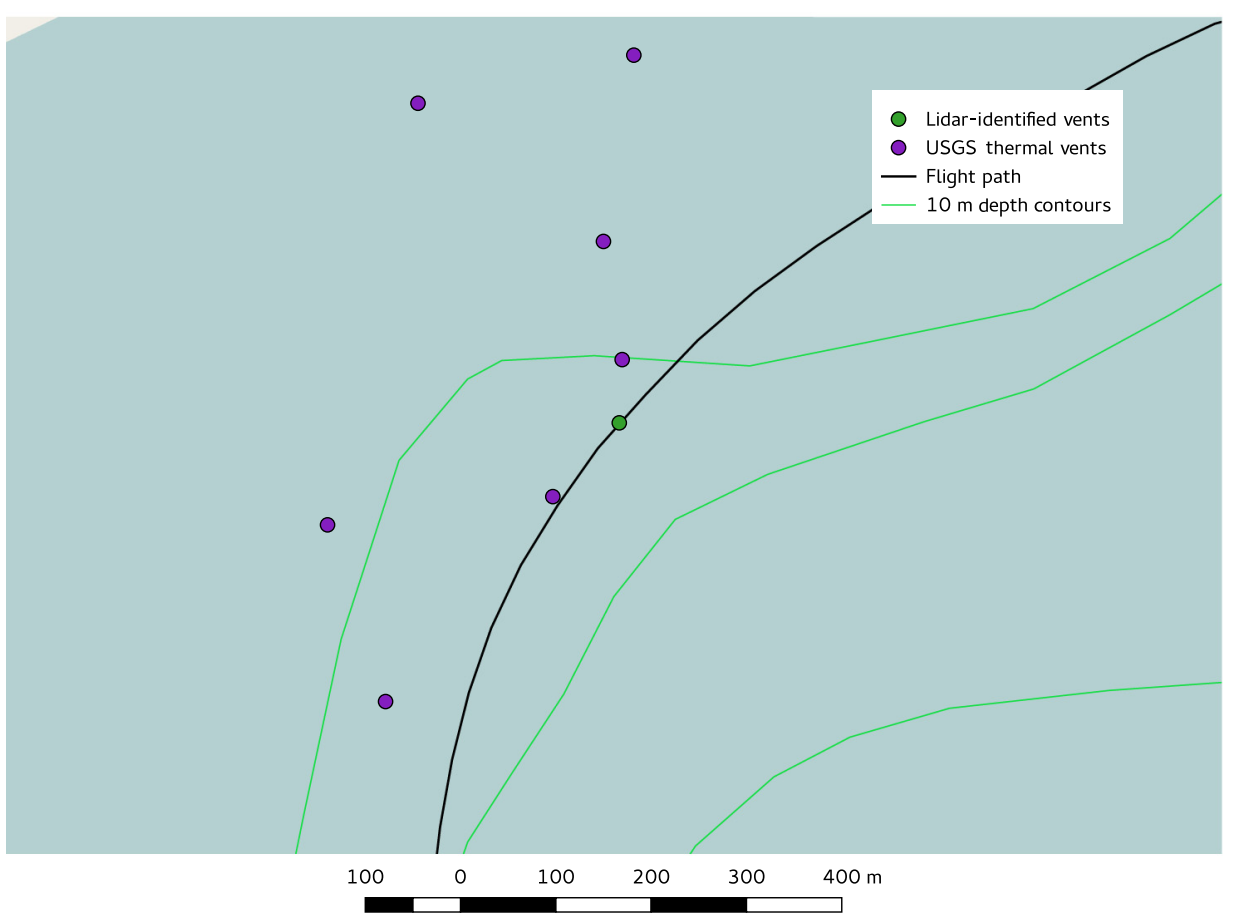

Fig. 7 A map showing USGS-identified thermal vents and the location of the vent shown in Fig. 固. The nearest USGS-identified thermal vent is $67 \mathrm{~m}$ away. Top of the maps point north. Thermal vent and bathymetry data from Ref. 8 . Base map data $\odot$ OpenStreetMap contributors.

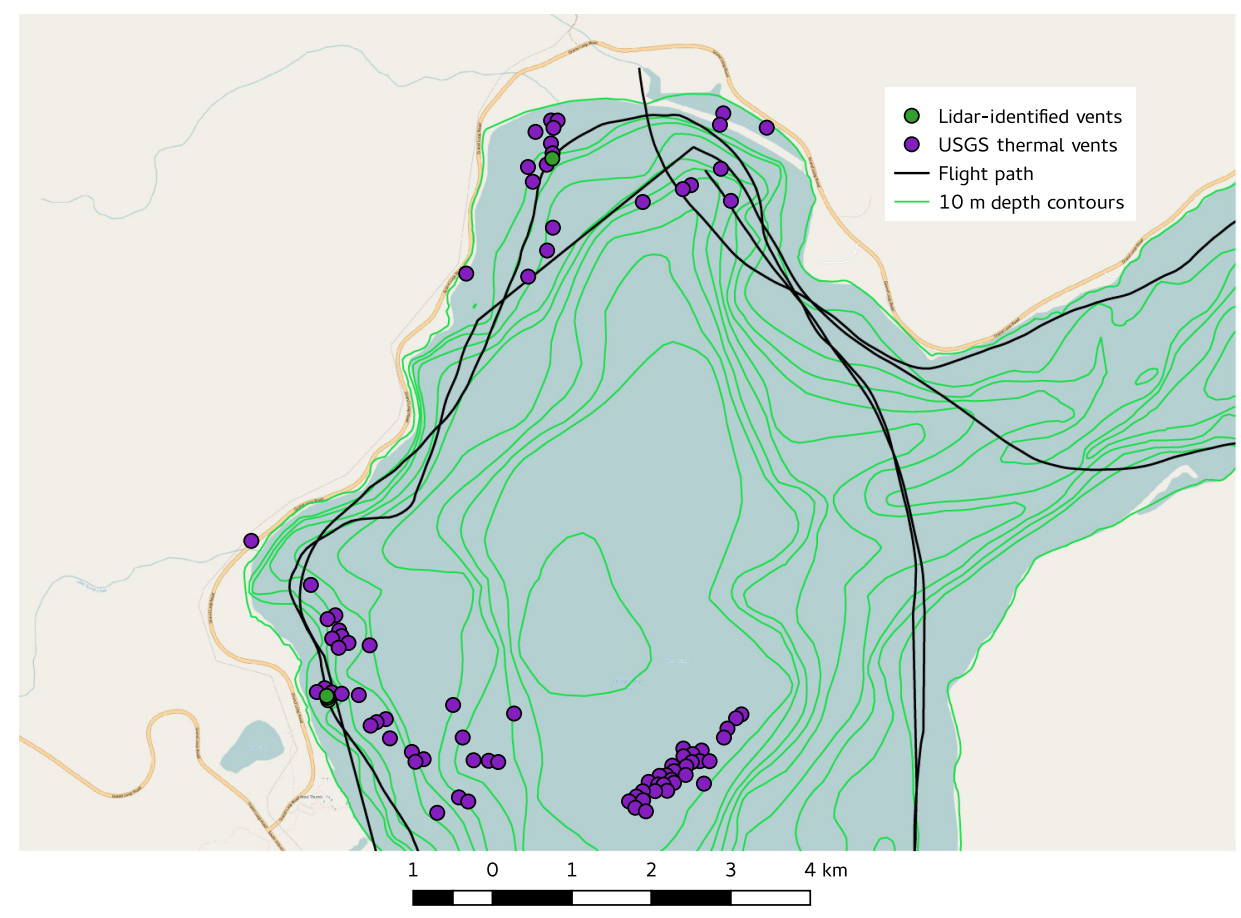

Fig. 8 An overview map showing USGS-identified thermal vents and the location of both lidaridentified vents. The scale on this map is much larger than the previous maps, and despite the proximity of some of the thermal vents to the flight path, they are actually quite some distance from the lidar beam. Top of the maps point north. USGS thermal vent and bathymetry data from Ref. B. Base map data (C) OpenStreetMap contributors. 


\section{Discussion and Conclusion}

We are not aware of any prior work discussing the detection of underwater thermal vents with lidar. The correlation of the location of the first possible vent shown in Figs. 目 and 3 with the USGS vent data, the surface plume, and the domal structure is strong evidence that this is indeed a thermal vent. While the USGS did not indicate that a thermal vent existed as close to the location of the second possible vent (shown in Fig. 6), the data appeared similar to the first with the existence of a domal structure with a hole in the center. It is possible that this vent is not active and thus was not included in the survey, or the plane was more severely banked than with the first vent and thus the position error was greater. The absence of a plume near the surface over the second feature and the lack of a bright return at the vent itself is further evidence that it may be dormant.

The narrow, vertical spikes at the bottom seen in the first vent data [Fig. 2(a)] could be "underwater chimneys" created by the thermal vent, as opposed to sediments in the vent water. Morgan and Remsen report the existence of underwater chimneys from thermal vents, but there is disagreement in the literature on whether these are active. Remsen reports active underwater thermal chimneys, several meters in length and between 10 and $20 \mathrm{~cm}$ in diameter. 咽 Morgan et al 1 reports the existence of chimneys but also states that none of these chimneys is currently known to be active.

It is clear that further investigation is needed. Are these indeed thermal vents? What creates the surface plume? What causes the bright, vertical returns to appear at the location of the vent? Ideally, a lidar flight would coincide with surface observations. Hopefully this is work that can be performed in the future. Once these questions are answered lidar could be used as a low-cost tool to identify the location of underwater thermal vents.

\section{Acknowledgments}

The authors wish to acknowledge the flight pilot, F. Richard Hauer, for his assistance in gathering the data. This work was supported by the Montana Research and Economic Development Initiative under Agreement No. 51040-MUSRI2015-01.

\section{References}

1. C. C. Remsen et al., "Sublacustrine geothermal activity in Yellowstone Lake: studies past and present," in Yellowstone Lake: Hotbed of Chaos or Reservoir of Resilience, pp. 192-212 (2002).

2. J. V. Klump et al., "The presence and potential impact of geothermal activity on the chemistry and biology of Yellowstone Lake, Wyoming," in Global Venting, Midwater and Benthic Ecological Processes, I. Babb and M. de Luca, Eds., pp. 81-98, National Oceanic and Atmospheric Administration, National Undersea Research Program, Rockville, Maryland (1988).

3. C. C. Remsen et al., "Hydrothermal springs and gas fumaroles in Yellowstone Lake, Yellowstone National Park, Wyoming," Nat. Geogr. Res. 6(4), 509-515 (1990).

4. L. A. Buchholz et al., "Employment of ROV techniques and scuba in Yellowstone Lake," in Diving for Science: Proc. of the American Academy of Underwater Sciences Fifteenth Annual Scientific Diving Symp., American Academy of Underwater Sciences, Mobile, Alabama (1995).

5. L. A. Morgan et al., "Exploration and discovery in Yellowstone Lake: results from highresolution sonar imaging, seismic reflection profiling, and submersible studies," J. Volcanol. Geotherm. Res. 122, 221-242 (2003).

6. L. S. Balistrieri et al., The Influence of Sublacustrine Hydrothermal Vent Fluids on the Geochemistry of Yellowstone Lake, U.S. Geological Survey Professional Paper 1717, Chapter F, Denver, Colorado (2007).

7. T. Yang et al., "Microbial communities and chemosynthesis in Yellowstone Lake sublacustrine hydrothermal vent waters," Front. Microbiol. 2, 130 (2011).

8. L. A. Morgan et al., "Bathymetry and geology of the floor of Yellowstone Lake, Yellowstone National Park, Wyoming, Idaho, and Montana,” Tech. Rep. Scientific Investigations Map 2973, U.S. Geological Survey (2007). 
9. M. R. Roddewig et al., "Dual-polarization airborne lidar for freshwater fisheries management and research," Opt. Eng. 56(3), 031221 (2017).

10. L. A. Morgan, Ed., Integrated Geoscience Studies in the Greater Yellowstone AreaVolcanic, Tectonic, and Hydrothermal Processes in the Yellowstone Geoecosystem, U.S. Geological Survey Professional Paper 1717, Chapter D, Denver, Colorado (2007).

11. J. H. Churnside, "Lidar signature from bubbles in the sea," Opt. Express 18(8), 8294-8299 (2010).

Michael R. Roddewig received his bachelor's degree from Michigan Tech in 2009 and his master's degree from the Colorado School of Mines in 2012. He earned his PhD in electrical engineering from Montana State University in 2017. He is a staff scientist at AdvR, Inc., Bozeman, Montana. This research was conducted while he was a $\mathrm{PhD}$ student at Montana State University. He is a member of SPIE.

James H. Churnside received his $\mathrm{PhD}$ in physics from the Oregon Graduate Center in Beaverton, Oregon. He is a researcher at the NOAA Earth System Research Laboratory, Boulder, Colorado, USA, where he conducts research on the development and applications of airborne lidar for oceanographic studies. He is a fellow of the OSA and SPIE.

Joseph A. Shaw received his PhD and MS degrees in optical sciences from the University of Arizona, his MS degree in electrical engineering from the University of Utah, and his BS degree in electrical engineering from the University of Alaska-Fairbanks. He is the director of the Optical Technology Center, professor of optics and photonics and of electrical and computer engineering, and affiliate professor of physics at Montana State University, Bozeman, Montana. He conducts research on the development and application of radiometric, polarimetric, and laser-based optical remote sensing systems. He is a fellow of the OSA and SPIE. 